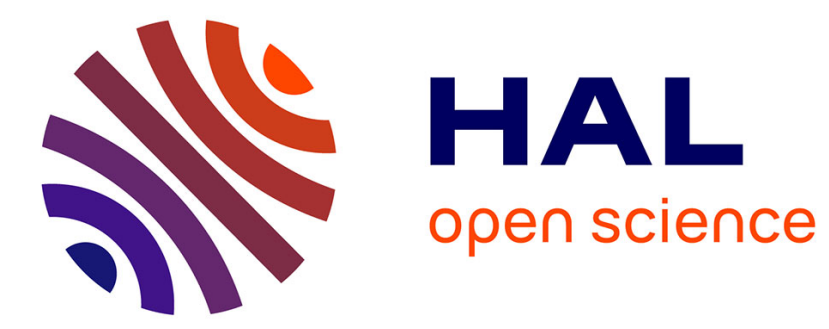

\title{
Interfaces in Silicides
}

F. d'Heurle

\section{- To cite this version:}

F. d'Heurle. Interfaces in Silicides. Journal de Physique IV Proceedings, 1996, 06 (C2), pp.C2-29-C246. 10.1051/jp4:1996205 . jpa-00254183

\section{HAL Id: jpa-00254183 https://hal.science/jpa-00254183}

Submitted on 1 Jan 1996

HAL is a multi-disciplinary open access archive for the deposit and dissemination of scientific research documents, whether they are published or not. The documents may come from teaching and research institutions in France or abroad, or from public or private research centers.
L'archive ouverte pluridisciplinaire HAL, est destinée au dépôt et à la diffusion de documents scientifiques de niveau recherche, publiés ou non, émanant des établissements d'enseignement et de recherche français ou étrangers, des laboratoires publics ou privés. 


\title{
Interfaces in Silicides
}

\author{
F.M. d'Heurle
}

IBM Research, PO. 218, Yorktown Heights, NY 10598, U.S.A. and Kungliga Tekniska Högskolan, Electrum 229, 16440 Kista, Sweden

\begin{abstract}
The role of interfaces with respect to the use of silicides in electronic technology is analyzed from two different points of view. To begin with interfaces of different nature, grain boundaries, stacking faults, etc... are examined in the perspective of their metallurgical properties as they affect silicide formation by solid state reaction, diffusion of silicon dopants, nucleation of the new phases.... While considering those metallurgical aspects, reference is made also to the integration of silicides in silicon device technology, and to the relations between metallurgical parameters and electrical properties, e.g. the density of stacking faults and the resistivity of $\mathrm{WSi}_{2}$. In a shorter second section the previous order is reversed: attention is focused on the electrical properties of silicide silicon interfaces in ohmic and rectifying contacts, and on the use of epitaxial silicides in metal base transistors, where one desires such perfect match between silicide layer and silicon as to allow the transfer of ballistic electrons across the layer.
\end{abstract}

\section{INTRODUCTION}

Because of their resistance to oxidation, various silicides have been investigated for use as structural materials in high temperature applications, or as protective layers for parts made for example of molybdenum. Such applications shall hardly be considered here. The domain of this presentation shall be confined to that of the current electronic technology, and to investigations motivated by that technology, where the silicides used either because of their good conductivity, or, and this is most important for our purpose, because the silicide-silicon interfaces have desirable electrical characteristics. This last topic, however, shall be mentioned only at the end of this paper where the main emphasis will be placed on the metallurgical properties of silicide interfaces. The roles of interfaces in the material behavior of silicides are many. Space limitations will require that the various topics be considered only briefly. Grain boundaries have been shown to play a significant role in the growth of silicide layers by metal silicon reactions; they also contribute to the redistribution of the doping impurities that are so important in silicon technology. Epitaxy between silicide and silicon may affect the nucleation of growing phases, and stabilize metastable forms of these new phases. Because of possible electronic applications a great deal of efforts has been spent on the formation of epitaxial layers of $\mathrm{CoSi}_{2}, \mathrm{NiSi}_{2}$, and various iron and rare-earth silicides; these will be considered separately. Some disilicides have structures similar to that of cobalt, with the result that phase transformations create stacking faults with extremely high densities. They affect considerably the electrical transport properties 
of these compounds. At the high temperatures required by silicon device fabrication, silicides may become morphologically unstable because of surface tension effects. In the presence of polycrystalline silicon, capillary effects have unexpected consequences.

The author does not know of specific works on the structure of grain boundaries in silicides, except for considerations of failures due to "low" temperature oxidation in structural silicide parts (pest phenomenon). However, it is to be anticipated that the high energy of formation requires good atomic match at grain boundaries in order to avoid unduly high specific interface energies; thus, the boundaries might be highly faceted. This has been discussed elsewhere [1]. Microscopic evidence of such faceting in oxides, see Figs. 4.3 and 4.4 in [2], may provide examples of what obtains in silicides also.

\section{METALLURGICAL CONSIDERATIONS.}

Diffusion, silicide growth, $\mathrm{Ni}_{2} \mathrm{Si}, \mathrm{CoSi}_{2}$ and others. Dopant diffusion in $\mathrm{CoSi}_{2}, \mathrm{TiSi}_{2}, \mathrm{WSi}_{2}$

The growth of new silicides phases from metal-silicon reactions may take several forms [3], but one of these, diffusion-controlled, is most easily understood (at least in its immediate aspects) and perhaps the most frequent. The thickness is proportional to the square root of time. One immediate question is whether diffusion occurs via grain boundaries or through the lattice. An early experiment [4] with a metallic marker revealed that in $\mathrm{Ni}_{2} \mathrm{Si}$, and by extension in other similar silicides $\left(\mathrm{Co}_{2} \mathrm{Si}, \mathrm{Pd}_{2} \mathrm{Si}\right.$ and $\left.\mathrm{Pt}_{2} \mathrm{Si}\right)$ growth proceeded by grain boundary diffusion. The study of the self diffusion of radiotracer nickel (and silicon) [5] also in $\mathrm{Ni}_{2} \mathrm{Si}$ confirmed that growth occurred via grain boundary diffusion. A similar study on $\mathrm{CoSi}_{2}$ led to the same conclusion [6]. Extension of these results [7], on the basis of the respective activation energies for self diffusion and for growth, shows that the diffusion-controlled growth of most silicides occurs via grain boundary transport. With other modes of growth (e.g. so-called reaction ratecontrolled) statements become more hazardous, but in as much as usually these growths take place in temperature ranges that are comparable to what obtains in diffusion-controlled growth, the attribution of transport to grain boundaries is probably valid in those cases as well. In all phenomena, particularly diffusion, associated with grain boundaries the question occurs of knowing whether the boundaries have the same composition as the lattice; the compositions are even in $\mathrm{CoSi}_{2}$ [8], and that may be true also of other compounds, probably all the more true as the heats of formation are high, the free energy versus composition curves sharp, and deviation from stoichiometry consequently costly, but one would like to have more experimental evidence. For a generalized analysis of the role of grain boundaries in phase growth, see [1].

The use of silicon in electronics is made possible by the special characteristics conveyed by various $\mathrm{n}$ and $\mathrm{p}$ dopants. In as much as silicides are used with doped silicon, it is important to know how the dopants behave inside those silicides. An early report [9] provided evidence of extensive redistribution of boron from doped polysilicon to an adjacent $\mathrm{WSi}_{2}$ layer, Fig. 1 . Boron was incorporated during the deposition of the polycrystalline silicon by CVD (chemical vapor deposition), then the $\mathrm{WSi}_{2}$ layer was deposited above, by similar means, at low temperature and therefore in an amorphous condition. During the subsequent annealings for diffusion purposes, it crystallized with relatively small grains. It is clear that the transport of boron into 


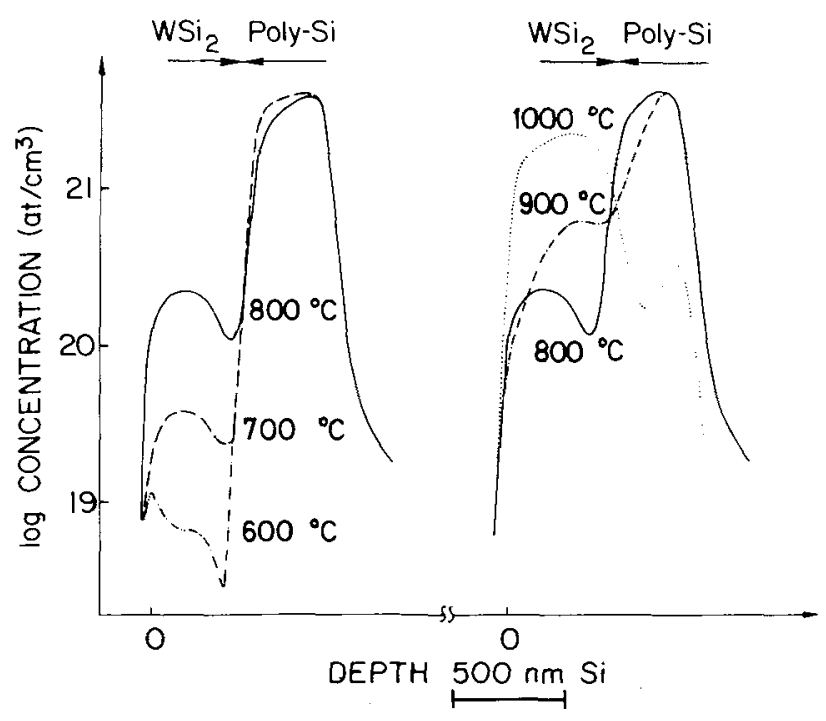

Figure 1 - A film of $\mathrm{WSi}_{2}$ was deposited over a layer of polycrystalline silicon doped with boron. After annealing at $1000{ }^{\circ} \mathrm{C}$ for 1 hour, most of the boron has been redistributed from the silicon to the silicide. Profiles corresponding to different annealing temperatures provide some evidence for the kinetics of the process. From [8].

the silicide occurred via grain boundary diffusion, since at the same annealing temperatures, boron implanted in $\mathrm{WSi}_{2}$, previously annealed to insure grain growth, shows little or no mobility. For studies of diffusion of dopants inside amorphous and crystallizing $\mathrm{WSi}_{2}$ and $\mathrm{TiSi}_{2}$ at low temperatures (about $500^{\circ} \mathrm{C}$, which is low for materials melting at about $2000{ }^{\circ} \mathrm{C}$ ) see $[10,11]$. Even in well annealed silicides, dopant diffusion is dominated by grain boundary transport, e.g. in $\mathrm{TiSi}_{2}$ and $\mathrm{CoSi}_{2}$ [12,13]; the model proposed is shown in Fig. 2. In $\mathrm{CoSi}_{2}$ where boron is a particularly fast diffuser, segregation of boron on the grain boundaries has been shown [8].

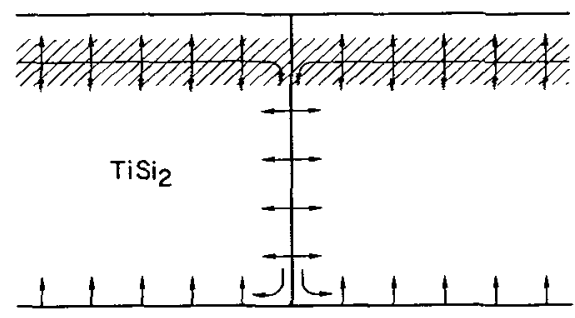

Si

Figure 2 - During annealing, a dopant implanted in a silicide layer (here $\mathrm{TiSi}_{2}$ ) get redistributed through rapid diffusion in the grain boundaries and along the interface between silicide and silicon. The process can be used to drive a dopant into the superficial layers of a silicon substrate. From [13]. 
Dopant diffusion is important in electronic technology because it affects the electrical characteristics of the devices. In the insulated gate field effect device illustrated in Fig. 3 modulation of the current between source and drain (left and right) depends on the work function of the polycrystalline silicon immediately above the gate oxide; transport of dopant from or to that polycrystalline silicon from the adjacent silicide (placed where it is to decrease the electrical resistance) will change the electrical parameters of the device. Many circuits nowadays use

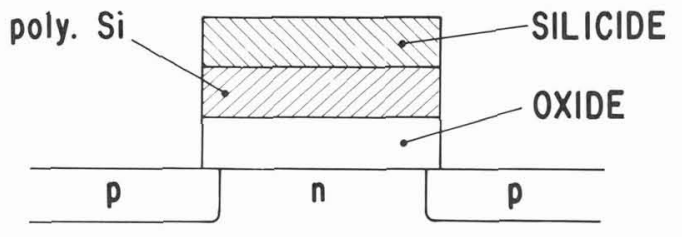

Figure 3 - The operating voltage of an insulated gate field effect device (IGFET or MOSFET) depends critically on the work function of the polycrystalline silicon electrode immediately over the gate oxide. During processing, transfert of dopant from the polycrystalline silicon to the overlying silicide (or vice versa) can have very deleterious effects on the working parameters of the device.

CMOS technology, illustrated in Fig. 4, where devices of opposite "polarities" are operating cojointly. The polycrystalline silicon on the gates are usually doped with $\mathrm{p}$ and $\mathrm{n}$ elements (one on each device). Obviously transport of dopant from one gate electrode to the other is most undesirable. Such transport of dopant can also affect the electrical characteristics of contacts.

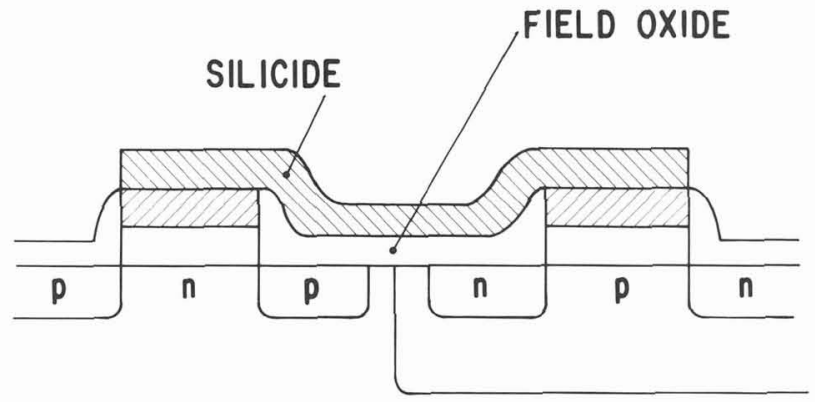

Figure 4 - The conditions described in Figure 3 become even more critical with complementary devices (CMOS). There, the dopant in the two electrodes will generally be of different polarities, $n$ and $p$. Transport of dopant along silicide interconnections may actually reverse the polarity of an electrode.

Indeed, this has been put to use [14] in a scheme as shown in Fig. 5, where the time required for the dopant implanted at one end of a silicide line to reach the contact between the silicide and single crystal silicon at the other end, and change its electrical characteristics, gave the measure of dopant diffusion in the silicide. For more practical information of this nature, see [15]. 


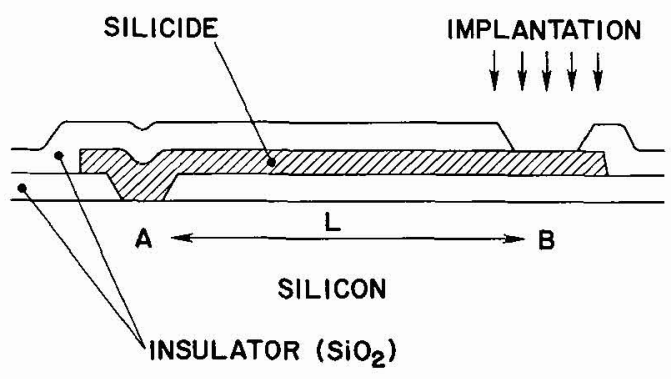

Figure 5 - Changes of the electrical characteristics of the silicide-silicon contact at the left, resulting from the transport of dopant implanted at the right in a silicide interconnection, can be used to measure the diffusion rate of a specific dopant in a silicide. By varying the transport length $\mathrm{L}$, and the annealing temperature and time, the diffusion characteristics of the dopant can be precisely determined. From [14].

Nucleation, PdSi, $\mathrm{NiSi}_{2}$.

Epitaxy between the forming silicide and silicon may affect preferred orientation, and through the possibilities of multiple positioning the grain size. Both of these factors may affect diffusion growth e.g. NiSi [16]. Preferred orientation will be a factor in lattice diffusion for most silicides with clearly anisotropic structures, but it also affects grain boundary diffusion even in perfectly isotropic (from a diffusion point of view) cubic crystals. However, in general these effects will be secondary. In order to see a major effect of interfaces on phase formation one must look at a phase with a nucleation controlled formation: PdSi. The reaction of silicon with a palladium film yields first of all $\mathrm{Pd}_{2} \mathrm{Si}$ that grows at low temperatures, some $200{ }^{\circ} \mathrm{C}$, by a diffusion controlled process. The equilibrium diagram palladium-silicon contains a eutectoid at about $700{ }^{\circ} \mathrm{C}$, where $\mathrm{Pd}_{2} \mathrm{Si}, \mathrm{PdSi}$ and silicon are in equilibrium (and below which $\mathrm{PdSi}$ is no more truly stable, although it can easily be quenched to room temperature). Upon heating a sample of $\mathrm{Pd}_{2} \mathrm{Si}$ on silicon to $700{ }^{\circ} \mathrm{C}$ nothing will happen since all phases are in equilibrium and any exchange between the phases would have no driving force $(\Delta G=0)$. That changes when the temperature is increased above $700^{\circ} \mathrm{C}$, but while $\Delta \mathrm{G}$ remains small the formation of PdSi requires the formation of a new interface from (I) $\mathrm{Si}-\mathrm{Pd}_{2} \mathrm{Si}$, to (II) $\mathrm{Si}-\mathrm{PdSi}$ and (III) $\mathrm{PdSi}-\mathrm{Pd}_{2} \mathrm{Si}$. The situation is similar to that encountered in classical nucleation theory where the formation of a new phase requires superheating (or cooling) so as to obtain a $\Delta G$ sufficiently big to overcome the increase in energy due to surface effects. It is here that interface effects become dominant. $\mathrm{Pd}_{2} \mathrm{Si}$ is hexagonal and grows epitaxially on (111) silicon, with a relatively low interface energy, so that in that case the increase in surface energy $\left(\Delta \sigma=\sigma_{\mathrm{II}}+\sigma_{\mathrm{II}}-\sigma_{\mathrm{I}}\right)$ due to the formation of PdSi will be big, and consequently (the activation energy for nucleation varies as $\Delta \sigma^{3}$ ) the superheating required for the formation of PdSi shall be big also, about 150 ${ }^{\circ} \mathrm{C}$. With silicon $(100)$ where there is no dominant epitaxy between silicon and $\mathrm{Pd}_{2} \mathrm{Si}$ the superheating is less, only some $35^{\circ} \mathrm{C}$ [17]. For a generalized study of these phenomena, see [18]. One should be careful about such interface nucleation effects: although $\mathrm{NiSi}_{2}$ (or $\mathrm{CoSi}_{2}$ ) can grow epitaxially on single crystal silicon (both 100 and 111) from $\mathrm{NiSi}$, it grows at lower temperatures $[19,20]$ on "amorphous" silicon, where epitaxy plays only a minor role if any. In 
this case the effect is not due to $\Delta \sigma$, which undoubtedly increases (in comparison to what obtains with crystalline silicon), but to the dominance of a greater $\Delta \mathrm{G}$ (the activation energy for nucleation varies as $1 / \Delta \mathrm{G}^{2}$ ) which is increased by the difference in free energies between single crystal and amorphous silicon.

\section{Epitaxy and metastable phases, $\mathrm{NiSi}$... $\mathrm{FeSi}_{2}$}

With thin films, surfaces and interfaces become important because surface and interface energy terms contribute a significant part of the overall free energy of the phase. Especially with single crystal substrates such as silicon an epitaxial interface may stabilize a metastable form of a phase usually not present in that particular form. The thickness limit is inversely proportional to the differences in free energies between the two phases, and proportional to the difference in specific energies between the two possible interfaces: silicon-stable phase, and siliconepitaxial metastable phase. That may depend on the orientation of the substrate. NiSi, which has the MnP structure, grows epitaxially on silicon (111) with the hexagonal NiAs structure (up to several $10 \mathrm{~nm}$ ) but not on silicon $(100)[16,17]$. FeSi and CoSi, normally with a complicated cubic structure and a large unit cell, have been grown epitaxially on silicon with the simple $\mathrm{CsCl}$ structure $[22,23]$. Epitaxial, metastable $\mathrm{FeSi}_{2}[24]$ with the $\mathrm{CaF}_{2}$ structure (like $\mathrm{NiSi}_{2}$ and $\mathrm{CoSi}_{2}$ ) is quite interesting in that it illustrates some fundamental points about the stability of phases. Metastable $\mathrm{FeSi}_{2}$ has a peak in the density of states curve at the Fermi level, which makes it metallic and unstable. In the stable phase, an orthorhombic distortion of the cubic symmetry breaks the cubic degeneracy of the quantum states, splits the density of state peak into two separate peaks, and makes the normal compound a semiconductor (with a band gap of about $0.9 \mathrm{eV})$. For an overall view of epitaxies in the silicon and iron-silicon compounds, many of them with metastable structures, see [25].

$$
\text { Epitaxy of } \mathrm{CoSi}_{2}, \mathrm{NiSi}_{2}, \mathrm{FeSi}_{2}, \mathrm{CrSi}_{2}, \mathrm{RESi}_{\mathrm{L} .7 .}
$$

Epitaxial phases need not assume a structure truly different from the stable one. Provided the symmetry and the atomic spacings of some planes of the silicide phase match those of the surface plane of the silicon substrate epitaxy can occur, so to speak, quite naturally. Since the atomic dimensions are rarely exactly the same for silicon and silicide, epitaxy requires that the latter undergoes some minor distortion which bears the name of pseudomorphism. The $\mathrm{CaF}_{2}$ structure of $\mathrm{CoSi}_{2}$ and $\mathrm{NiSi}_{2}$ is very similar to the diamond cubic structure of silicon, but their lattice parameters are slightly smaller. Therefore, ideal epitaxy with a perfectly coherent interface requires that on (100) planes the two silicides should become slightly tetragonal, and on (111) planes slightly rhombohedric. Above a certain critical thickness the elastic energy stored in the silicide layers exceeds that required for the formation of interface dislocations. Then, the epitaxy ceases to be quite ideal and the silicides recover lattice dimensions closer to the truly relaxed values. This is the well known van der Merwe mechanism [26]. When forming these two silicides via metal-silicon reaction the formation of the monosilicides precedes that of the final compound. However, as we have seen the $\Delta \mathrm{G}$ for the transformation is small and the transformation becomes nucleation-controlled. This means that the disilicides form from discrete nucleation centers followed by some lateral spreading. Thus, the final layers are composed of domains grown from unique centers that meet on some internal boundaries. These could simply be antiphase boundaries, or actually no boundaries at all, but as a matter 
of fact, ideal single crystal films rarely result from such nucleation and growth processes. It has been found that electrically better layers can be formed via molecular beam techniques, whereby the desired silicide is initially deposited with its stoichiometric composition, thus circumventing nucleation. Partly because the subject was well fit for theoretical and experimental investigations, partly because of technical interest (e.g. in the preparation of metal base transistors) the literature on these two epitaxial disilicides has grown quite huge. The reader shall find all the necessary information in two recent reviews [27,28]. The epitaxy of $\mathrm{Pd}_{2} \mathrm{Si}$ on $(111)$ silicon has already been mentioned above [17]. Another hexagonal silicide has been grown epitaxially on the same substrate, $\mathrm{CrSi}_{2}$ [29]; the critical thickness for a totally coherent interface is small, about $4 \mathrm{~nm}$. Epitaxy of the rare-earth silicides, hexagonal, with a composition such as $\mathrm{RESi}_{1.7}$ has attracted a great deal of attention, for example [30]. One compound, already discussed above in its metastable phase $\mathrm{FeSi}_{2}$ has also been grown epitaxially in its stable, orthorhombic, semiconducting phase $[31,32]$. The relationships on the two main silicon orientations are: $\mathrm{FeSi}_{2}(100) / / \mathrm{Si}(001)$, with $\mathrm{FeSi}_{2}[010] / / \mathrm{Si}[110]$, and $\mathrm{FeSi}_{2}$ (101)// $\mathrm{Si} \mathrm{(111),}$ with $\mathrm{FeSi}_{2}[010] / / \mathrm{Si}[011]$. The unit cell dimensions, $\mathrm{a}=0.986 \mathrm{~nm}, \mathrm{~b}=0.779 \mathrm{~nm}$, and $\mathrm{c}=$ $0.783 \mathrm{~nm}$, specify the three orthorhombic axes. Silicide layers obtained via ion implantation into silicon, followed by the formation of discrete silicide precipitates and Oswald ripening of the precipitates into continuous epitaxial layers could also be discussed here, but the mention of a review [33] will satisfy our present needs. On the general issue of the epitaxy of silicides on silicon the reader should turn to $[34,35]$.

$$
\text { Stacking faults, } \mathrm{WSi}_{2}, \mathrm{MoSi}_{2} \ldots \mathrm{TiSi}_{2} \text { and } \mathrm{ZrSi}_{2}
$$

A series of seven silicides from $\mathrm{TiSi}_{2}$ to $\mathrm{WSi}_{2}$ (but excluding $\mathrm{ZrSi}_{2}$ and $\mathrm{HfSi}_{2}$ ) are built very much like the ordered compound $\mathrm{Cu}_{3} \mathrm{Au}$. They are constituted by hexagonal close-packed planes of atoms in which each metal atom is surrounded by six silicon atoms, with a configuration as in $\mathrm{Cu}_{3} \mathrm{Au}$. In both cases the planes have the correct stoichiometry 1 to 2 , and 1 to 3 , respectively which is obtained simply by the proper repartition of the minority atoms. Then different structures are obtained as with hexagonal and face centered cubic metals by different stacking of these stoichiometric planes. In these disilicides, the stacking is such that the atoms of a superposed layer have only two, not three neighbors below, for a final coordination number of $10(6+2+2)$. Examination of the structures show that this is necessary in order to avoid that metal atoms should become neighbors to each other, instead they are surrounded by 10 silicon atoms. The stacking can be $\mathrm{ABCA}$, hexagonal in $\mathrm{TaSi}_{2}$ for example. In $\mathrm{MoSi}_{2}$ and $\mathrm{WSi}_{2}$ that stacking order is encountered only at low temperatures (below about $600{ }^{\circ} \mathrm{C}$ ) but at high temperatures the order becomes $\mathrm{ABA}$, which curiously gives a tetragonal structure. $\mathrm{TiSi}_{2}$, that will be discussed again later, in its normal phase (structure C54) has the stacking $\mathrm{ABCDA}$, with a very slight distortion of the hexagonal planes, less than $1 \%$, which causes the structure to be orthorhombic. The stacking order follows the electron to atom ratio, so that a solution of $50 \% \mathrm{TiSi}_{2}$ and $\mathrm{WSi}_{2}$ shall have the hexagonal structure of $\mathrm{TaSi}_{2}$. The hexagonal to tetragonal transformations of $\mathrm{MoSi}_{2}$ and $\mathrm{WSi}_{2}$ is quite similar to the better known transformation of cobalt, the differences being dictated by the respective coordination numbers 10 and 12. This similarity caused this author to engage in a search for stacking faults in the silicides, with the knowledge that near the transformation temperature the free energy of formation of the faults should be zero and the density extremely high. That search remained vain for quite a long time until the advent of high resolution electron microscopy and the possibilities of lattice im- 
aging allowed one to see that at the transformation temperature the density of faults was almost infinitely high, being limited only by the lattice spacing [36,37]. This is accompanied by extremely high resistivities, several $100 \mu \Omega-\mathrm{cm}$ instead of the normal value about $30 \mu \Omega-\mathrm{cm}$, and a negative temperature coefficient of resistance. This latter effect is due to localization phenomena, not as believed by some, to the hexagonal phase being semiconducting. With the structures being dictated by e/a ratios, it is to be anticipated that in alloys of these disilicides the stacking fault density could become very high also, which is verified to be true [38].

In its normal $\mathrm{C} 54$ form, $\mathrm{TiSi}_{2}$ belongs to the disilicides discussed in the preceding paragraph. That compound has the habit of regularly forming [39,40] in the $\mathrm{C} 49$ structure of $\mathrm{ZrSi}_{2}$ and $\mathrm{HSSi}_{2}$, which is unfortunate because the resistivity of that phase hovers around $50 \mu \Omega-\mathrm{cm}$, instead of $13 \mu \Omega-\mathrm{cm}$ for the C54 phase. The orthorhombic C49 structure is complicated, being composed alternatively along the long $\mathrm{b}$ axis of three dimensional layers with the composition TiSi, and planar layers of silicon atoms. Because the a and $\mathrm{c}$ unit cell dimensions are almost identical, the planes of silicon atoms have a nearly square symmetry. It is readily seen therefrom that two successive layers of "TiSi" can easily be rotated by $90^{\circ}$ with respect to each other with no perturbation in nearest atomic neighbors (silicon atoms). The only direct distortion caused by such rotation would be a small mutual adjustment of the a and c dimensions. Indeed, if the density of such faults becomes sufficiently high the structure ceases to be orthorhombic to become tetragonal. This type of fault can also be described in term of a translation along the [101] direction $[39,41,42]$. In spite of their high densities these faults do not cause any catastrophic increase in resistivity.

Surface tension, agglomeration and "inversion".

The silicides that are used as thin films either for contacts or as conductors in silicon device technology are exposed to high temperatures during processing. This leads to morphological instabilities, since the stable form of any solid is not a thin film, but a spheroid whose precise shape is modulated by the anisotropy of its surface energy. The phenomenon, called agglomeration, was first observed in $\mathrm{TiSi}_{2}$ [43]. It becomes worse as the films become thinner, and for films some $50 \mathrm{~nm}$ thick manifests itself at about $900^{\circ} \mathrm{C}$. The films do not ball up into spheres of course, but break into separated islands so that the resistance increases to infinity. The same phenomenon is observed with the technologically significant $\operatorname{CoSi}_{2}$, but is not a problem up to $1000^{\circ} \mathrm{C}$ with a refractory compound such as $\mathrm{WSi}_{2}$. It is simply a matter of lowering the energy level of the system (film and substrate) by reducing the surface energy. It is good to remember some fundamental aspects. With a perfectly isotropic medium (any liquid), a small rod breaks easily into individual droplets because any fluctuations in the cylindrical shape is stable and tends to grow. The opposite is true of a uniform planar film, since any fluctuation in its shape necessarily increases its surface and its surface energy. All the more so, as the specific surface energy is high. This has lead to a paradoxical situation where those that have modeled the agglomeration of thin films arrive at the conclusion that the higher the surface energy the more stable the film. Yes, but one should not lose sight of the fact that it is the surface energy that drives agglomeration, and the higher the surface energy the higher the driving force. So whether one considers the initial and final states, or the dynamic transition between these states one arrives at opposite conclusions. Modelling involves the considerations of grain boundaries, and there too the models are somewhat challenging in that they lead to the 
conclusion that the smaller the grain size the more stable the film (because the grain boundary groves in films with sufficiently small grain size are shallow); there too, dynamic conditions yield conclusions that challenge thermodynamics.

The literature on silicide films contains several worthwhile articles on the question of agglomeration [44-46]. In [45], the authors report on the surface and interface energies of silicides on silicon, determined from the knowledge of the surface energies of silicon, and the experimental measurement of the dihedral angles of silicide islands on silicon surfaces: $\mathrm{TiSi}_{2}$ surface $-1200 \mathrm{ergs} / \mathrm{cm}^{2}$ and $800 \mathrm{ergs} / \mathrm{cm}^{2}$ respectively on silicon (100) and silicon (111) (the different values imply preferential orientations, and measurements on different surface planes), and for the interfaces $900 \mathrm{ergs} / \mathrm{cm}^{2}$ on silicon (100) and $600 \mathrm{ergs} / \mathrm{cm}^{2}$ on silicon (111). For $\mathrm{ZrSi}_{2}$ on (111) silicon the surface energy is $900 \mathrm{ergs} / \mathrm{cm}^{2}$, and the interface energy 800 ergs $/ \mathrm{cm}^{2}$. The models used for silicide agglomeration are quite worth considering, but the readers should consult also [47] on the agglomeration of oxide films. Advanced electronic technology requires always smaller dimensions, so that conductors, including silicide conductors are presently designed with a width approaching $100 \mathrm{~nm}$. Naturally, the conditions of agglomeration already bad for continuous planar films become worse as the line widths decrease [48-50]. There again the reader should pay attention to a paper treating of the problem in oxide fibers [51]. Agglomeration need not be complete to be catastrophic. This author knows of one example where a $\mathrm{TiSi}_{2}$ film was used as an etch-stop in device fabrication. But the etching procedure progressed through the thickness of the device below: small pinholes had formed at three grain junctions in the silicide film as the very first stage of agglomeration. This phenomenon is treated in [51,53]. The rate of agglomeration is greatly reduced in single crystal films. Thus the discovery [54] that a small addition of titanium to cobalt enhances the formation of epitaxial $\mathrm{CoSi}_{2}$ resulted in a great deal of activity and publications. Yet the role of titanium remains quite obscure [55].

Another problem, "inversion", is also associated with capillary phenomena, but with an origin distinctly different from that of agglomeration. Agglomeration and inversion happen in the same systems, and at not too different temperatures, so that they tend to be confused with one another. But they are and should be clearly distinguished. When heating a silicide film (or a metal film for that matter) in contact with a film of polycrystalline silicon previously deposited at about $575^{\circ} \mathrm{C}$, one observes a very curious phenomenon, the inversion in positions of the two films, with the silicon film initially below appearing on top. The phenomenon has nothing to do with the surface energy of the silicide, but with the very high "internal" energy of the silicon in the polycrystalline film, that because it was prepared (by chemical vapor deposition) at low temperature is characterized by a high degree of disorder, not only very small grains, but a very high density of stacking faults, and probably of dangling bonds as well. The driving force for grain growth is therefore extremely high. However, in silicon the mobility remains extremely low at temperatures below $1000^{\circ} \mathrm{C}$, excluding all possibilities of intrinsic grain growth at lower temperatures. Yet because of the relatively high mobility of silicon atoms in the silicide (or metal) film in bilayers, grain growth and recrystallization of the silicon film actually occur via silicon transport through the silicide. The processus is such that at the end the films have exchanged positions. A review [56] indicates that the phenomenon is not limited to silicides; it occurs with metal films as well. As mentioned earlier, in the literature agglomeration and inversion tend to be confused with each other. However, if one heats a film couple of 
polycrystalline silicon and silicide while monitoring its resistance, one observes during inversion a) an increase in resistance, followed by a decrease probably due to some form of Oswald ripening of the silicide grains [as above, 33] into a more continuous and uniform layer, and $b$ ) at higher temperature,the final increase of resistance to infinity as the silicide film finally agglomerates (the driving force then depends only on the interface energy between silicide and silicon, the free surface of the silicide being inexistent at this final stage). The dynamic phenomenon of inversion is complex [see e.g. 57], but its origin is clear and different from that of agglomeration. The difference in temperatures is due to the fact that inversion requires mainly the diffusion of one atomic species, the most mobile usually silicon with the disilicides but metal as well as in inversion with $\mathrm{NiSi}$ [56], while agglomeration which mandates a change of shape of the silicide depends directly on the mobility of the two atomic species.

\section{Surface adsorption, segregation of $\mathrm{Si}$}

It is generally true that in binary solid solutions the surface and the internal interfaces (grain boundaries, and stacking faults - Susuki effect) do not have the same composition as the lattice because of the segregation (or adsorption) of one of the components to these surfaces and interfaces. In binary compounds such as the silicides, one question that has already been referred to above concerns the composition of the grain boundaries. There exists quite a lot of evidence pointing to the segregation of silicon at the free surface of silicides. Surface scientists working with thin layers of silicides on silicon generally observe a surface almost entirely composed of silicon. Upon removal of the segregated surface layer by sputtering, further annealing results in the formation of a new silicon surface. That is true for $\mathrm{NiSi}_{2}$ and $\mathrm{CoSi}_{2}$ $[58,59]$. Surface renewal of silicon does not imply that it occurs via silicon diffusion $[60,61]$, but that is a different matter. Confirmation of the presence of a silicon layer at the surface of (111) and (100) $\mathrm{NiSi}_{2}$ was also obtained by Low Energy Electron Diffraction [62,63]. Somewhat similar observations were made with thick $(100 \mathrm{~nm})$ films of $\mathrm{TiSi}_{2}$ on silicon [64]. Low energy sputtering of the surface with the sample held at $500-600^{\circ} \mathrm{C}$ causes the silicide layer to move deeper into the silicon substrate while a) the silicide thickness remains constant and b) silicon is steadily eroded away. It is not immediately clear whether this is due purely to surface segregation of silicon or to preferential sputtering, or to both mechanisms simultaneously, but this author inclines towards the first of these processes. (In the case of $\mathrm{TiSi}_{2}$, the required matter transport clearly occurs via silicon diffusion). The surface composition of silicides is certainly quite interesting theoretically, with the silicon rich surface verifying the idea that the element with the lowest surface energy should be preferentially segregated. From a practical point of view the interest is less, although the nature of the top surface would be important if on top of an epitaxial silicide layer one wanted to grow some epitaxial silicon. Presently that is not an urgent matter. A subject more technically important is the understanding of what happens at the surface of a silicide film being prepared by chemical vapor deposition, and that involves the chemisorption of the different vapor species at the surface [65]. That is, however, out of the scope of this article with its strong metallurgical bias.

\section{Oxidation, pest phenomenon.}

Silicide grain boundaries appear to play a significant role in a domain totally different from the electronic technology that has been considered up to now: that is the use of silicides (and other 
oxidation resistant compounds, aluminides for example) for structural parts used at high temperatures, perhaps turbine blades and such. At high temperatures, above $1000-1100^{\circ} \mathrm{C}$ silicides are well protected by a continuous layer of $\mathrm{SiO}_{2}$, but the thermodynamic and kinetic conditions are such that at low temperatures this is no longer true, so that the solid silicide may literally fall apart into a powder, through a process that has received the name of "pest" phenomenon. This mode of failure first studied years ago [66] continues to attract a lot of attention [67]. On single crystal silicides, the failure mode leads to different morphologies and proceeds more slowly $[66,68]$ than on polycrystalline samples. The situation is not very clear (hence the continuous supply of new publications). The diffusion of oxygen along grain boundaries, the resulting embrittlement of these boundaries, and the formation of grain boundary oxides all appear to play a role $[69,70]$. It is likely that oxide precipitates causing tensile stresses across the boundaries increase the grain boundary diffusion of oxygen and accelerate the process [71]. Certainly, the last word on this fascinating and very deleterious phenomenon, the thermodynamics of which are considered in [72], remains to be written.

\section{ELECTRICAL CHARACTERISTICS, SCHOTTKY CONTACTS.}

Silicides are used in electronic technology as conductors because of their relatively low resistivities (except for the semiconducting silicides) and of their resistance to oxidation during processing in oxidizing atmospheres. That aspect need not concern us beyond what has already been said. Silicides are also used for their contact properties to silicon. At least two books $[73,74]$ are devoted to this topic, but the subject is also lengthily discussed in books on device technology such as [75]. The electrical characteristics of silicide-silicon interfaces shall be briefly analyzed here. Let us recall that our understanding of these electrical interface phenomena is based on the work of two pioneers, Davidov and Schottky [76,77].

Rectifying and ohmic contacts.

The conditions of the electron bands in metal or silicide are described in Fig. 6 for rectifying contacts. The current $\mathbf{J}$ is given by Eq. 1:

$$
J=A * T^{2} \exp -\frac{q \Phi_{B}}{k T} \times\left(\exp -\frac{q V}{k T}-1\right)
$$

where $J$ is the current, $A^{*}$ is the effective Richardson constant for thermionic emission, $\Phi_{B}$ is the Schottky barrier height, $V$ the applied voltage and the other parameters have their usual meaning. The Schottky barriers to $\mathrm{n}$ and $\mathrm{p}$ silicon should add to the band gap of silicon, 1.1 eV. In Fig. 6, the bending of the bands in the semiconductor (silicon) occurs over the Debye length, $\lambda_{\mathrm{D}}$, which is a function of the density of charge carriers, $\mathrm{N}_{\mathrm{d}}$ :

$$
\lambda_{\mathrm{D}}=\left(\frac{\mathrm{kT} \epsilon}{\mathrm{N}_{\mathrm{d}} \mathrm{e}^{2}}\right)^{1 / 2}
$$


where $\epsilon$ is the low frequency permittivity of silicon. The Debye length is inversely proportional to the square root of the density of charge carriers, the density of donors in $\mathbf{n}$ type silicon. If that density is sufficiently high, the Debye length becomes so short that electrons can tunnel from the semiconductor into the metal. Then the contact ceases to be rectifying and becomes ohmic. The resistance of the contact $R_{c}$ becomes:

$$
\mathrm{R}_{\mathrm{c}}=\frac{\mathrm{k}}{\mathrm{qA} \mathrm{A}^{*} \mathrm{~T}} \exp \left(\frac{\mathrm{q} \Phi_{\mathrm{B}}}{\mathrm{kT}}\right)
$$
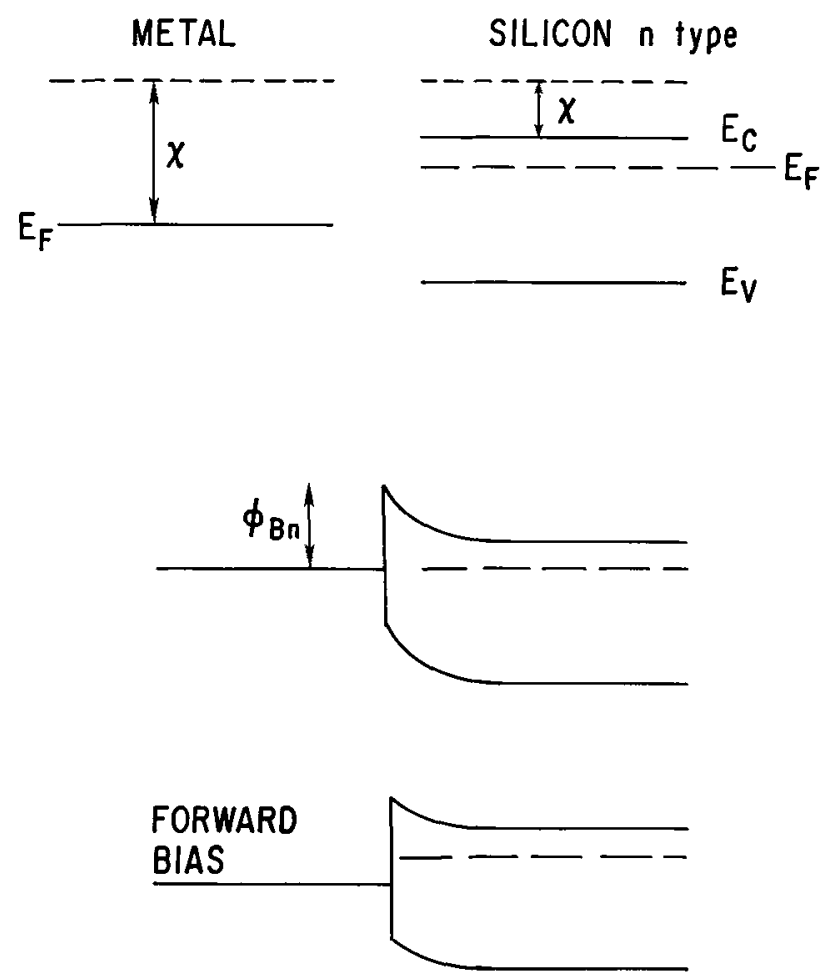

Figure 6 - Schematic representation of the band conditions characteristic of a rectifying Schottky contact to $n$ type silicon. On top the metal and semiconductor considered separately, below the changes after contact has been established, and at the bottom the same under conditions of forward bias.

It is seen from Eq. 3 that the resistance decreases as $\Phi_{B}$ decreases. In bipolar devices as well as in CMOS Insulated Gate Transistors, one desires to fabricate simultaneously ohmic contacts to both $p$ and $n$ silicon, which dictates that one should chose silicides with $\Phi_{B}$ close to the middle of the band gap, namely equal to about $0.55 \mathrm{eV}$. The barrier height of titanium disilicide is satisfactory for this purpose. There are some difficulties, in particular since $\mathrm{TiB}_{2}$ is such an extremely stable compound boron used as a dopant in p-type silicon tends to migrate out of the silicon in the contact area in order to reduce the silicide and form the diboride instead. That 
reduces $\mathrm{N}_{\mathrm{d}}$ and increases the contact resistance accordingly. The problem is minimized in the most advanced technology where the dimensions are very small, so that in order to avoid unwanted dopant diffusion and respect the dimensions, the temperatures and durations of any heat treatments are extremely limited (low thermal budget). Platinum monosilicide is extensively used in bipolar technology in spite of its high barrier height to n-type silicon, $0.87 \mathrm{eV}$. That is due to several factors, one of these has to do with fabrication sequences and etching characteristics, but there is also a real technical demand, based on a specific character of Schottky barrier diodes. Usual p-n diodes are dual carrier (holes and electrons) devices. Current is made to flow with the application of a potential, and upon removal of this potential the carriers return to equilibrium via recombination, which is a time consuming process. Because Schottky diodes are one carrier devices, they are intrinsically faster. One takes advantage of this property in bipolar devices by installing a Schottky diode in parallel with base and collector (this is called a clamp) in order to decrease the operating time. For this purpose the barrier height of PtSi is almost ideally suited.

According to Fig. 6, the Schottky barrier height should be directly related to the work function of the metal (or silicide). Experimentally that is not what is observed, the reason being that surface states pin the Fermi level of the carriers. The theory is complex, experimental verification difficult, so that articles on the subject seem to appear endlessly. The situation is quite ideal for "scientific" magicians who try to relate measured Schottky barrier heights to other parameters, such as the heats of formation of compounds, etc... and who receive an undue share of attention. It is clear that there is some relation between Schottky barrier heights, and work functions, and electronegativities, and heats of formation of compounds, and melting points, and eutectic temperatures. Thus, there should exist some correlations between Schottky barriers and these parameters, but unless justified by sound logic, these correlations belong to the domain of poor sociology, not physics. For an example of a serious treatment of the subject, see $[78,79]$. The matter can be extremely subtle. In the epitaxy of $\mathrm{NiSi}_{2}$ on (111) silicon, as in all such systems, the silicide can assume two positions (usually referred to in the literature on silicides as $A$ and $B$ ), where one of the position is a twin of the other, the two being related by a rotation of $180^{\circ}$. For metals, let us say silver on gold, such twin positioning does not affect the first atom neighbors; but with the diamond cubic- $\mathrm{CaF}_{2}$ epitaxy the twinning results in small differences in atomic bonding. As shown in Fig. 7 [27], the two positions yield Schottky barrier heights different by more than $0.1 \mathrm{eV}$.

Actually many factors affect the characteristics of Schottky diodes. It is clear that an uneven silicide-silicon interface, with protuberances causing high fields, will cause a diode to become leaky in reverse voltage conditions. In a recent study [80], the authors explore the relation between metallurgical and electrical characteristics of diodes prepared with $\mathrm{TiSi}_{2}$. The subject appears to be inexhaustible: one more paper on PtSi, already well belabored for many years, was published in October 1995 [81]. As a final point in this discussion of Schottky barriers one notes that almost all metals and their silicides are rectifying to n-type silicon, namely the barrier height to n-type silicon is higher than that to p-type. This is not true, however, of the rare-earth silicides and of the silicides of elements akin to the rare-earth metals, yttrium and scandium [82] that have barrier heights of about $0.4 \mathrm{eV}$ to $\mathrm{n}$-type silicon. 


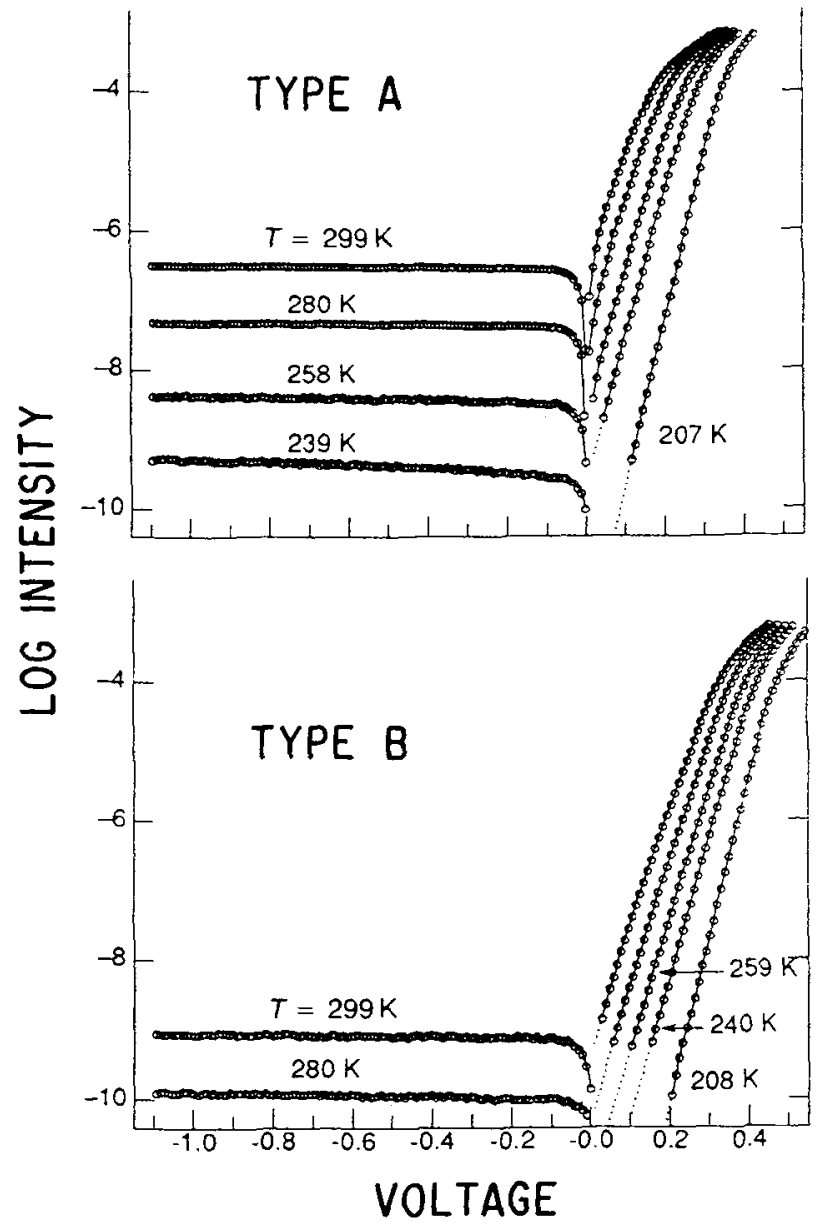

Figure 7 - The current voltage characteristics of the contacts between $\mathrm{n}$ silicon (111) and $\mathrm{A}$ or $\mathrm{B}$ type $\mathrm{NiSi}_{2}$. From [27].

Others, ballistic devices, infrared detectors, etc...

Silicides are not used only in "large scale" electronic technology. Engineers interested in infrared detectors can beneficially use silicide to silicon contacts because that allows them (within limits) to select the barrier height specific to the radiation to be monitored [83]. That depends on the same electrical characteristics as discussed previously with undoubtedly some specific requirements as well. There is another domain, of very limited (perhaps zero) technological interest but quite fascinating otherwise, that of metal base transistors. Such possible applications motivated the intense work on epitaxial $\mathrm{CoSi}_{2}$ or $\mathrm{NiSi}_{2}$, and buried layers of these compounds. The challenge is to achieve perfect single crystals, thin and without any pinholes, and perfect interfaces, in order to achieve high operating speeds through the transfer of ballistic carriers across the silicide layers and their two interfaces. Calculations of the structure and 
transfer characteristics of epitaxial silicide layers are presented in [84]. Much of the work on the epitaxy of $\mathrm{FeSi}_{2}$ in its stable form was motivated by the pious (but probably vain) hope that this semiconducting compound had a direct band gap and could be used for electroluminescence. The formation of single crystals would increase the efficiency by reducing the possibility of nonradiative recombination at defects such as grain boundaries, while epitaxy would allow the use of light emitting diodes in integrated silicon optoelectronic devices [see e.g. 85-87].

\section{CONCLUSIONS}

Undoubtedly, too little is known about the properties, e.g. diffusion characteristics, of intermetallic compounds in general and of silicides in particular. Yet, the above survey of the role of interfaces in silicides should demonstrate that simple metallurgical principles throw considerable light on the behavior of these fascinating and useful materials. For those sitting at the border between science and technology, it is sobering that with silicides as in other domains the understanding of a phenomenon, e.g. the nucleation of rain, does not necessarily assure that it can be satisfactorily controlled. We know that agglomeration is due to surface tension effects, but we must look somewhat blindly for the correct "surfactant" that would allow thin films of $\mathrm{TiSi}_{2}$ to be used above $900{ }^{\circ} \mathrm{C}$. The discussion of the electrical properties of silicides and silicide-silicon interfaces provides insight in the relations between the two distinct domains of metallurgy and electronic engineering. This, however, is not a plea in favor of a mixing of the disciplines, which results in everyone knowing a little about everything and nothing well. Rather, it is a plea for collaboration across intellectual borders (and national as well).

\section{ACKNOWLEDGEMENTS}

It is a pleasure to express my gratitude to R. Tung for his gracious authorization to reproduce Fig. 7. Many are those, colleagues, friends, teachers and students, who should be thanked for their contributions to my understanding of the behavior of silicides. When it comes to interfaces, one must be singled out: P. Gas. Those who would judge as to master and disciple according to age would be wrong, here the old man is the pupil. Amongst the others, C. S. Petersson, J. Philibert, O. Thomas and S.-L. Zhang must be acknowledged separately. Over the flow of years their help, both moral and scientific, has been immensely valuable.

\section{REFERENCES}

1 - d'Heurle F. M., Gas P. and Philibert J., Mater. Res. Soc. Symp. Proc. 343 (1994) 181.

2 - Norton M. G. and Carter C. B., in Materials Interfaces, Atomic-Level Structure and Properties, edited by Dieter Wolf and Sidney Yip (Chapman \& Hall, London, 1993) p. 151.

3 - d'Heurle F. M. and Gas P., J. Mater. Res. 1 (1986) 205.

4 - Finstad T. J., Thin Solid Films 51 (1978) 411.

5 - Ciccariello J.-C., Poize S. and Gas P., J. Appl. Phys. 67 (1990) 3315.

6 - Barge T., Gas P. and d'Heurle F. M., J. Mater. Res. 10 (1995) 1134.

7 - Gas P. and d'Heurle F. M., Appl. Surf. Sci. 73 (1993) 153.

8 - Malchère A., Gas P., Haut C., Larére A., Nguyen T. T. and Poize S., Appl. Surf. Sci. 53 (1991) 132. 
9 - Jahnel F., Biersack J., Crowder B. L., d'Heurle F. M., Fink D., Isaac R. D., Lucchese C. J. and Petersson C. S., J. Appl. Phys. 53 (1982) 7372.

10 - Stanis C., Thomas O., Gas P., Charai A., LeGoues F. K., Cotte J. and d'Heurle F. M., J. Vac. Sci. Technol. A 10 (1992) 907.

11 - d'Heurle F. M., Cotte J., Gas P., Göltz G., Stanis C. and Thomas O., Appl. Surf. Sci. 73 (1993) 167.

12 - Gas P., Deline V., d'Heurle F. M., Michel A. and Scilla G., J. Appl. Phys. 60 (1986) 1634.

13 - Thomas O., Gas P., Charai A., LeGoues F. K., Michel A., Scilla G. and d'Heurle F. M., J. Appl. Phys. 64 (1988) 2973.

14 - Chu C. L., Saraswat K. C. and Wong S. S., IEEE Trans. Elect. Dev. 39 (1993) 131.

15 - Maex K., Materials Science and Engineering R11 (1993) 53.

16 - d'Heurle F. M., Petersson C. S., Baglin J. E., LaPlaca S. J. and Wong C. Y., J. Appl. Phys. 55 (1984) 4208.

17 - Hutchins G. and Shepela A., Thin Solid Films 18 (1973) 343.

18 - d'Heurle F. M., J. Mater. Res. 3 (1988) 167.

19 - Lien C. D., Nicolet M.-A. and Lau S. S., phys. status solidi a 8 (1984) 123.

20 - Lien C. D., Nicolet M.-A. and Lau S. S., Appl. Phys. A 34 (1984) 249.

21 - Föll H., Ho P. S. and Tu K. N., Philos. Mag. A 45 (1982) 31.

22 - von Känel H., Mäder K. A., Müller E., Onda N. and Sirringhaus H., Phys. Rev. B 45 (1992) 13807.

23 - von Känel H., Schwartz C., Goncalves-Conto S., Müller E., Miglio L., Tavazza F.and Malegori G., Phys. Rev. Lett. 74 (1995) 1163.

24 - von Känel H., Satdler R., Sirringhaus H., Onda N. and Henz J., Appl. Surf. Sci. 53 (1991) 196.

25 - Onda N., Sirringhaus H., Goncalves-Conto S., Schwarz C., Zehnder S. and von Känel H., Appl. Surf. Sci. 73 (1993) 124.

26 - Matthews J. W., in Epitaxial Growth edited by J. W. Matthews (Academic Press, New York, 1975) vol.2, p. 573.

27 - Tung R., in Materials Interfaces: Atomic-Level Structure and Properties edited by D. Wolf and S. Yip (Chapman \& Hall, London 1992) p. 550.

28 - von Känel H., Materials Science Reports 8 (1992) 193.

29 - Vantomme A., Nicolet M.-A., Long R. G., Mahan J. E. and Pool F. S., Appl. Surf. Sci. 73 (1993) 146.

30 - Duboz J.-Y., Badoz P.-A., Perio A., Oberlin J.-C., Arnaud d'Avitaya F., Campidelli Y. and Chroboczek J. A., Appl. Surf. Sci. 38 (1989) 171.

31 - Reader A. H., Duchateau J. P. W. B., Timmers J. and Hakkens F. J. G., Appl. Surf. Sci. 73 (1993) 131.

32 - Derrien J., Chevrier J., Le Thanh Vinh, Berbezier I., Giannini C., Lagomarsino S. and Grimaldi M. G., Appl. Surf. Sci. 73 (1993) 90.

33 - Mantl S., Materials Science Reports 8 (1992) 1.

34 - Zur A., McGill T. C. and Nicolet M.-A., J. Appl. Phys. 57 (1985) 600.

35 - Chen L. C. and Tu K. N., Mat. Sci. Rep. 6 (1991) 53.

36 - d'Heurle F. M., LeGoues F. K., Joshi R. and Suni I., Appl. Phys. Lett. 48 (1986) 332.

37 - LeGoues F. K., d'Heurle F. M., Joshi R. and Suni I., Mater. Res. Soc. Symp. Proc. 54 (1986) 51.

38 - Gas P., Tardy J., LeGoues F. K. and d'Heurle F. M., J. Appl. Phys. 61 (1987) 2203. 
39 - Beyers R. and Sinclair R., J. Appl. Phys. 57 (1985) 5240.

40 - d'Heurle F. M., Gas P., Engström I., Nygren S., Östling M. and Petersson C. S., IBM Research Report RC 11151 (1985).

41 - Jia C. L., Jiang J. and Zong X. F., Philos. Mag. A 59 (1989) 999.

42 - Bourret A., d'Heurle F. M., LeGoues F. K. and Charai A., J. Appl. Phys. 67 (1990) 241.

43 - Ting C. Y., d'Heurle F. M., Iyer S. S. and Fryer P. M., J. Electrochem. Soc. 133 (1986) 2621.

44 - Xiao Z. G., Rozgonyi G. A., Canovai C. A. and Osburn C. M., Mater. Res. Soc. Symp. Proc. 202 (1991) 101.

45 - Sukow C. A. and Nemanich R. J., J. Mater. Res. 9 (1994) 1214.

46 - Xiao Z. G., Rozgonyi G. A., Canovai C. A. and Osburn C. M., J. Mater. Res. 7 (1992) 269.

47 - Miller K. T., Lange F. F. and Marshall D. B., J. Mater. Res. 5 (1990) 151.

48 - Norström H., Maex K. and Vanhellemont P., J. Vac. Sci. Technol. B8 (1990) 1223.

49 - Xiao Z. G., Rozgonyi G. A., Canovai C. A. and Osburn C. M., J. Mater. Res. 7 (1992) 269.

50 - Wang Q. F., Osburn C. M., Smith P. L., Canovai C. A. and McGuire G. E., J. Electrochem. Soc. 140 (1993) 200.

51 - Miller K. T. and Lange F. F., Acta Metall. 37 (1989) 1343.

52 - Génin F. Y., Mullins W. W. and Wynblatt P., Acta Metall. 40 (1992) 3239.

53 - Agrawal D. C. and Raj R., Acta Metall. 37 (1989) 2035.

54 - Lawrence M., Dass A., Fraser D. B. and Wei C.-S., Appl. Phys. Lett. 58 (1991) 1308.

55 - Hong F, and Rozgonyi G. A., J. Electrochem. Soc. 141 (1994) 3480.

56 - Nygren S. and d'Heurle F. M., Solid State Phenomena 23 \& 24 (1992) 81.

57 - Allen L. H., Tu K. N., Feldman L. C. and Mayer J. W., Phys. Rev. B 41 (1990) 8213.

58 - Hinkel V., Sorba L., Haak H., Horn K. and Braun W., Appl. Phys. Lett. 50 (1987) 1257.

59 - Schowenberg F. D., Lin T. L., Fathauer R. W. and Grunthaner P. J., Appl. Phys. Lett. 55 (1989) 1314.

60 - d'Heurle F. M. and Thomas O., Appl. Phys. Lett. 53 (1988) 2269.

61 - d'Heurle F. M., Appl. Phys. Lett. 55 (1989) 1804.

62 - Yang W. S., Jona F. and Marcus P. M., Phys. Rev. B 28 (1983) 7377.

63 - Wu S. C., Wang Z. Q., Li Y. S., Jona F. and Marcus P. M., Solid State Communications 57 (1986) 687.

64 - Motakef S., Harper J. M. E., d'Heurle F. M. and Gallo T., J. Appl. Phys. 70 (1991) 2660.

65 - Southwell R. P. and Seebauer E. G., J. Vac. Sci. Technol. A 13 (1995) 221.

66 - Aitken E. A., in Intermetallic Compounds edited by J. H. Westbrook (John Wiley, New York, 1967) p. 491.

67 - Doychak J., in Intermetallic Compounds, Principles and Practice edited by J. H. Westbrook and R. L. Fleischer (John Wiley, New York, 1995) vol 1, p. 977.

68 - Chou T. C. and Nieh T. G., Scripta Metall. Mater. 27 (1992) 19.

69 - Tolpygo V. K. and Grabke H. J., Scripta Metall. Mater. 28 (1993) 747.

70 - Brumm M. W., Grabke H. J. and Wageman, Corrosion Sci. 36 (1994) 37.

71 - Gangulee A., Philos. Mag.22 (1970) 865.

72 - d'Heurle F. M., J. de Phys. (1995).

73 - Rhoderick E. H. and Williams R. H., Metal-Semiconductor Contacts (Clarendon Press, Oxford, 1988). 
74 - Heinisch H. K., Semiconductor Contacts (Clarendon Press, 1984).

75 - Sze S. M., Physics of Semiconductor Devices (John Wiley, New York, 1981) pp. 258, 304.

76 - Davidov B., J. Phys. USSR 1 (1939) 167.

77 - Schottky W., Naturwiss. 26 (1938) 843.

78 - Tersoff J., Phys. Rev. B 32 (1986) 6968.

79 - Tersoff J., in Metallization and Metal-Semiconductor Interfaces edited by I. P. Batra (Plenum Press, New York, 1988) p. 281.

80 - Reva P., Nassiopoulos A. G. and Travlos A., J. de Phys. IV 4, Colloque C6 (1994) 93.

81 - Lahnor P., Seiter K., Schulz M., Dorsch W. and Scholtz R., Appl. Phys. A 61 (1995) 369.

82 - d'Heurle F. M., Aboelfotoh M. O., Pesavento F. and Petersson C. S., Appl. Surf, Sci. 53 (1991) 237.

83 - Kumar K. S., Silicides, in Intermetallic Compounds, Principles and Practice, edited by J. H. Westbrook and R. L. Fleischer (John Wiley, New York, 1995) vol. 2, p. 232.

84 - Hamann D. R., in Metallization and Metal-Semiconductor Interfaces edited by I. P. Batra (Plenum Press, New York, 1988) p. 195.

85 - Chevrier J., Natoli J. Y., Berbezier I., Ronda A. and Derrien J., Solid State Phenomena 32-33 (1993) 39.

86 - Duboz J.-Y., Badoz P.-A., Rosencher E., Henz J., Ospelt M., von Känel H. and Briggs A., Appl. Phys. Lett. 53 (1988) 788.

87 - Duboz J.-Y., Badoz P.-A., Hens J. and von Känel H., J. Appl. Phys. 68 (1990) 2346. 